\title{
Diffuse Absorbing Beryllium Coatings Produced by Magnetron Sputtering
}

David D. Allred

allred@byu.edu

C. M. Egert

Follow this and additional works at: https://scholarsarchive.byu.edu/facpub

Part of the Astrophysics and Astronomy Commons, and the Physics Commons

\section{Original Publication Citation}

C.M. Egert and D.D. Allred, "Light Absorbing Beryllium Coating Produced by Magnetron Sputtering," Stray Light in Optical Systems, Robert P. Breault, Editor, Proceedings of SPIE 1331, 17-178 (199). http://spiedigitallibrary.org/proceedings/resource/2/psisdg/1331/1/

17_1?isAuthorized=no http://dx.doi.org/1.1117/12.22676

\section{BYU ScholarsArchive Citation}

Allred, David D. and Egert, C. M., "Diffuse Absorbing Beryllium Coatings Produced by Magnetron Sputtering" (1990). Faculty Publications. 1194.

https://scholarsarchive.byu.edu/facpub/1194

This Peer-Reviewed Article is brought to you for free and open access by BYU ScholarsArchive. It has been accepted for inclusion in Faculty Publications by an authorized administrator of BYU ScholarsArchive. For more information, please contact ellen_amatangelo@byu.edu. 
Diffuse Absorbing Beryllium Coatings Produced by Magnetron Sputtering

\author{
C. M. Egert \\ Optics MODIL, Oak Ridge National Laboratory \\ Oak Ridge, TN 37831 \\ D. D. Allred \\ Dept. of Physics and Astronomy, Brigham Young University \\ Provo, UT 84602
}

\begin{abstract}
Beryllium coatings with varying thicknesses and columnar grain sizes were deposited by low temperature magnetron sputtering and wet chemically etched to enhance diffuse absorption of light. After etching these coatings exhibited a matte black surface finish and low specular reflectance (below $2 \%$ ) in the IR up to a critical wavelength dependent upon the original grain size of the coating. Extremely thick coatings $(350 \mu \mathrm{m})$ with original grain sizes of 10 to $12 \mu \mathrm{m}$ were produced which exhibited specular reflectances below $0.5 \%$ up to $50 \mu \mathrm{m}$ wavelength and a Lambertian. BRDF at $10.6 \mu \mathrm{m}$ averaging $4.3 \times 10^{-3}$ ster $^{-1}$. Scanning electron micrographs are presented for etched and unetched beryllium coatings which showed the etching process produces roughness and porosity over several size scales simultaneously with the maximum size scale limited by the initial coating grain size and thickness. This technique for. producing diffuse absorbing baffle materials has great versatility in choice of coating material and substrate and can be expected to provide optical system designers with a variety of material options for stray light management.
\end{abstract}

\title{
1. Introduction
}

Most currently available metallic baffle materials require modification of the bulk material often using electrochemical techniques in order to produce a diffuse absorbing surfaces. Martin black, perhaps the best example of such materials, is produced by anodization of an aluminum surface. We report here the development of a new approach to producing diffuse absorptive metallic coatings for stray light management. This process consists of two major steps: Low temperature sputter deposition of a columnar beryllium coating, followed by a selective wet chemical etching to further enhance porosity and increase diffuse scatter and absorption of incident light. While this approach is general and can be used with most any material which can be sputtered and chemically etched, only diffuse absorbing beryllium coatings are discussed here.

Diffuse absorptive materials often use surface roughness or porosity to trap, scatter, and absorb incident light. This process is most effective when the surface features have a size comparable to or slightly larger than the wavelength of the incident light. It has long been recognized that deposition processes such as sputtering produce columnar surface features with some porosity. The size of these columns and the existence of porosity depends primarily on the deposition conditions such as temperature and pressure, but also on overall coating thickness. Generally low temperature deposition enhances the formation of gross columnar structures and increasing thickness results in increasing column size. For example, studies of beryllium coating structure produced at low temperatures by magnetron sputtering indicate a linear relationship between column size and coating thickness. ${ }^{1}$ It is this feature of low temperature sputter deposition that is taken advantage of here to produce diffuse absorbing coatings. 


\section{Experimental Details}

Beryllium coatings were produced on $5 \mathrm{~cm}$ diameter beryllium substrates by low temperature sputter deposition using a dedicated sputtering system shown schematically in Fig. 1 . A 15 cm diameter magnetron sputtering gun was located within a $30 \mathrm{~cm}$ diameter stainless steel vacuum chamber. The system was rough pumped by two cryosorption pumps operated in series. After the crossover pressure was reached, a gate valve was opened and a cryopump continued evacuating of the system. Sputter deposition was started when the base pressure in the chamber was in the low $10^{-5}$ torr range. Beryllium coatings were produced by magnetron sputtering at 10 mtorr argon pressure. Deposition rates varied from $5 \AA / s$ to $65 \AA / s$ depending on the coating thickness required, as did the source substrate separation which varied from $20 \mathrm{~cm}$ to $8 \mathrm{~cm}$. The temperature of the substrates being coated was not controlled during deposition, but did not exceed $150^{\circ} \mathrm{C}$. A variety of coatings with different thicknesses were produced for this study and are listed in Table 1.

First a set of three coating runs were made at different thicknesses with three beryllium substrates per run. Each coated sample was divided into two halves and etched for different times as indicated in Table 1 to produce diffuse absorptive surfaces. The first digit in the sample numbers listed in table 1 gives the run number, the letter (A, B, or C) represents the sample and the final number (a 1 or 2) represents the particular half of the sample. Only two samples were etched from each coating run. The third sample from each run (sample $C$ ) was used as a control and not etched. Following this first set of experiments a group of beryllium substrates were coated with an extremely thick layer of $350 \mu \mathrm{m}$ of beryllium. These coating runs are denoted by the preface BQ followed by a sample number in Table 1.

Four different wet chemical etching treatments were investigated to enhance porosity of the deposited beryllium coatings. While several etchants were found to successfully enhance the diffuse absorbing properties of the coatings, the most successful was a found to be a mixture of HF and ethanol. This solution was used for all subsequent experiments reported here. Coated samples were etched for pre-determined period of time depending on coating thickness, typically between $45 \mathrm{~s}$ and $180 \mathrm{~s}$. After etching the samples were immediately rinsed in deionized water, followed by an ethanol rinse before being dried by a stream of pressurized dry air. An uncoated beryllium sample was also etched as a control.

Following this surface treatment coated samples were evaluated for optical performance by measuring IR reflectance and BRDF. Specular IR reflectance was obtained using a. Perkin-Elmer 983G Spectrophotometer at near normal incidence and wavelengths between 2 and $50 \mu \mathrm{m}$. BRDF scatter measurements were made using a TMA Associates' Complete Angle Scatterometer (CASI) at $10.6 \mu \mathrm{m}$ wavelength and an angle of incidence of $30^{\circ}$. The size of the irradiated area for BRDF measurement was $5 \mathrm{~mm}$ square. Coated, but unetched beryllium samples were also characterized optically as controls. Finally, etched beryllium coatings were characterized by scanning electron microscopy to determine the nature of surface features and porosity.

\section{Optical Properties of Diffuse Absorbing Beryllium Coatings}

Coated samples were visually examined prior to etching and appeared, at near normal incidence, to have a uniformly matte gray appearance typical of thick beryllium coatings. As the sample was rotated away from normal the coating appeared shinier, while rotation in the opposite direction made the coating appear darker. This behavior is expected for a coating consisting of columnar grains with an highly oriented and faceted surface morphology. After etching the coatings appeared to be much darker than before. Rotation of the sample away from normal resulted in a slight 
Table 1. Summary of Beryllium Coatings Used in Baffle Development Study

\begin{tabular}{|c|c|c|c|}
\hline $\begin{array}{l}\text { Sample } \\
\text { Number }\end{array}$ & $\begin{array}{l}\text { Thickness } \\
(\mu \mathrm{m})\end{array}$ & $\begin{array}{l}\text { Etch Time } \\
\text { (sec) }\end{array}$ & Notes \\
\hline 1-B2 & 1 & 60 & \\
\hline $1-C$ & 1 & 0 & control \\
\hline 2-B2 & 5 & 90 & \\
\hline $2-C$ & 5 & 0 & control \\
\hline 3-A1 & 25 & 180 & \\
\hline 3-A2 & 25 & 120 & \\
\hline 3-B1 & 25 & 65 & \\
\hline 3-B2 & 25 & 30 & \\
\hline $3-C$ & 25 & 0 & control \\
\hline$B Q-4$ & 350 & 180 & \\
\hline$B Q-6$ & 350 & 0 & control \\
\hline
\end{tabular}

increase in brightness for short etch times. Increasing etching time usually resulted in darker appearance; while still further etching resulted in complete removal of the coating. The best etched diffuse absorptive samples had a "black velvet" appearance. A similar etching treatment applied to an uncoated beryllium control sample resulted in a bright matte gray finish with no enhanced diffuse absorption observed even when etched for as long as 10 minutes. This observation indicates the importance of the beryllium coating for producing diffuse absorbing surface features.

Specular IR reflectance measurements are presented in Figs. 2 through 4 . In Fig. $2 a$ the IR reflectance for sample $2-C$, an unetched beryllium coating, is shown. This sample specular reflectance was similar to polished beryllium except at wavelengths below $10 \mu \mathrm{m}$ were the natural surface roughness of the coating resulted in considerable scatter out of the detector acceptance cone. Reflectance curves for unetched control samples from runs 1 and 3 were similar to that presented in Fig. 2a. Figs. 2b, $3 a$ and $3 b$ are reflectance plots for increasing thickness $(1 \mu \mathrm{m}, 5 \mu \mathrm{m}$, and $25 \mu \mathrm{m}$, respectively) representing the best etching results from each coating run. The etched samples exhibited a flat, low reflectance region below a critical wavelength. The thicker coatings had a larger low reflectance regions extending to longer wavelengths. For example, sample 1-B2 had reflectance below $2 \%$ at wavelengths less than $2.7 \mu \mathrm{m}, 2-\mathrm{B} 2$ at wavelengths less than $17 \mu \mathrm{m}$, and 3-A1 at wavelengths less than $21 \mu \mathrm{m}$. Finally the IR reflectance of the much thicker coating (sample BQ-4) is shown in Fig. 4. The average specular reflectance for this sample was $0.41 \%$ for wavelengths between $2 \mu \mathrm{m}$ and $50 \mu \mathrm{m}$.

The effect of increasing etch time on reflectance is illustrated in Fig. 5 which is a plot of reflectance measured at four wavelengths as a function of etch time for a constant thickness of $25 \mu \mathrm{m}$. The average column size in a sputtered beryllium coating of this thickness was expected to be 3 to $5 \mu \mathrm{m}$ across. For smaller wavelengths (below $20 \mu \mathrm{m}$ ) reflectance dropped rapidly as a function of etch time. Larger wavelengths required longer etch time before reflectance was minimized. At $40 \mu \mathrm{m}$ wavelength, which was much larger than the average column size in this coating, increasing etch time resulted only in a slow, non-monotonic decrease in reflectance.

BRDF scatter measurements at $10.6 \mu \mathrm{m}$ are shown in Fig. 6 for the $350 \mu \mathrm{m}$ thick beryllium coating (sample BQ-04). Here BRDF is plotted as a function of angle measured from specular for two locations, center and edge, of the same sample. Also shown is the BRDF instrument background signal obtained without a sample present in the scatterometer. This BRDF plot for BQ-4 shows the 
Lambertian character of the scatter signal typical of thick, etched beryllium coatings. No statistically significant increase in scattered signal was observed at $0^{\circ}$, the specular reflectance angle. The average BRDF from $-30^{\circ}$ to $+30^{\circ}$ was $4.7 \times 10^{-3}$ ster $^{-1}$. For comparison, Martin black typically exhibits a BRDF of about $1 \times 10^{-3}$ ster $^{-1}$ at $10.6 \mu \mathrm{m}$ measured using the same scatterometer.

\section{Scanning Electron Microscopy of Diffuse Absorbing Beryllium Coatings}

A series of scanning electron micrographs taken of samples from run 3 is shown in Fig. 7 for different etch times. Reflectance data from these same samples was previously.discussed and presented in Fig. 5. Fig. 7a shows the coating surface at 10,000X before etching. The coating had isotropic columnar grains with dimensions between 3 and $5 \mu \mathrm{m}$. There is also evidence of some porosity between columns. Figs. $7 \mathrm{~b}, 7 \mathrm{c}$, and $7 \mathrm{~d}$ are successive micrographs of the coatings after etch times of $30 \mathrm{~s}, 65 \mathrm{~s}$ and $180 \mathrm{~s}$, respectively. As etch time increased from Fig. $7 \mathrm{~b}$ to $7 \mathrm{~d}$, the amount of porosity between grains also increased due to a reduction in the size of the columnar grains. Simultaneously, the individual grains were also attacked during etching resulting in the evolution of a porous microstructure within the columnar grains themselves. It was this production of micro-roughness and porosity on many different size scales of the coating that resulted in the a diffuse absorbing behavior effective over a range of wavelengths. However, porosity cannot increase beyond the original grain size or thickness of the coating and thus there is a maximum feature size and coating thickness which is capable of diffusely scattering and absorbing light. Hence, the thin coatings (runs 1, 2, and 3) with correspondingly small grain sizes cannot be effective in diffusely scattering and absorbing light at longer wavelengths; while thicker coatings (BQ runs) with larger grain size are more effective.

Similar scanning electron micrographs (at 2000X magnification) of the much thicker unetched and etched coatings are shown in Fig. 8. Fig. 8a shows the unetched surface morphology of sample BQ6. Here the columnar grains have anisotropic shapes approximately $10 \mu \mathrm{m}$ to $12 \mu \mathrm{m}$ along their major dimension. Again etching (Fig. 8b) creates porosity between columns while attacking individual grains again creating roughness and porosity over a range of size scales. Because of both the larger initial grain size and greater thickness, excellent diffuse absorptive behavior is observed out to $50 \mu \mathrm{m}$.

\section{Discussion}

We have shown that it is possible to produce diffuse absorbing surfaces by sputter deposition of beryllium at low temperatures followed by wet chemical etching to enhance diffuse scatter and absorption. The wavelength range over which these coatings are effective was shown to be dependent on thickness and columnar grain size of the original coating. Thicker coatings which have larger columnar grains are diffuse absorbing out to longer wavelengths when compared with thin coatings with smaller column sizes. Attack within the columnar grains by wet chemical etching produced porosity over a variety of size scales which diffusely scatter and absorb light at a variety of wavelengths.

There are several advantages to the approach described here for making diffuse absorptive baffle materials. First, use of a low temperature sputter deposition process allows a wide variety of materials to be used as substrates. Many currently available baffle materials require specialized surface treatment of a particular substrate material; for example, Martin Black requires use of an aluminum substrate. In our work we have applied diffuse absorptive beryllium coatings to a variety of substrates including aluminum, fused silica, and SiC. This versatility allows choice of a substrate material to be based on other criteria than stray light control requirements. Important design criteria such as cost, mechanical strength, stiffness, handleability and producibility now can also be considered. Also, if the mechanism postulated here for diffuse absorbing behavior of these coatings are valid, this 
technique should be applicable to a variety of coating materials which can be sputtered to produce a columnar structure and chemically etched. Finally, sputter deposition of beryllium produces a baffle coating with greater transparency to $x$-ray radiation than other currently available baffle materials or paints which is important for future $x$-ray optics applications including lithography.

\section{References}

1. C. M. Egert and J. G. Gooch, "The Evolution of Sputtered Beryllium Coating and Surface Microstructure." Internal ORNL Report MMES/USASDC-88-6, June 1988.

\section{Acknowledgements}

This work was sponsored by the Strategic Defense Initiative Organization through the Optics Manufacturing Operations Development and Integration Laboratory (MODIL) and the U. S. Army Strategic Defense Command under U. S. Department of Energy Interagency Agreement Nos. 1855-1562A1 and 1896-1562-A1, respectively. 


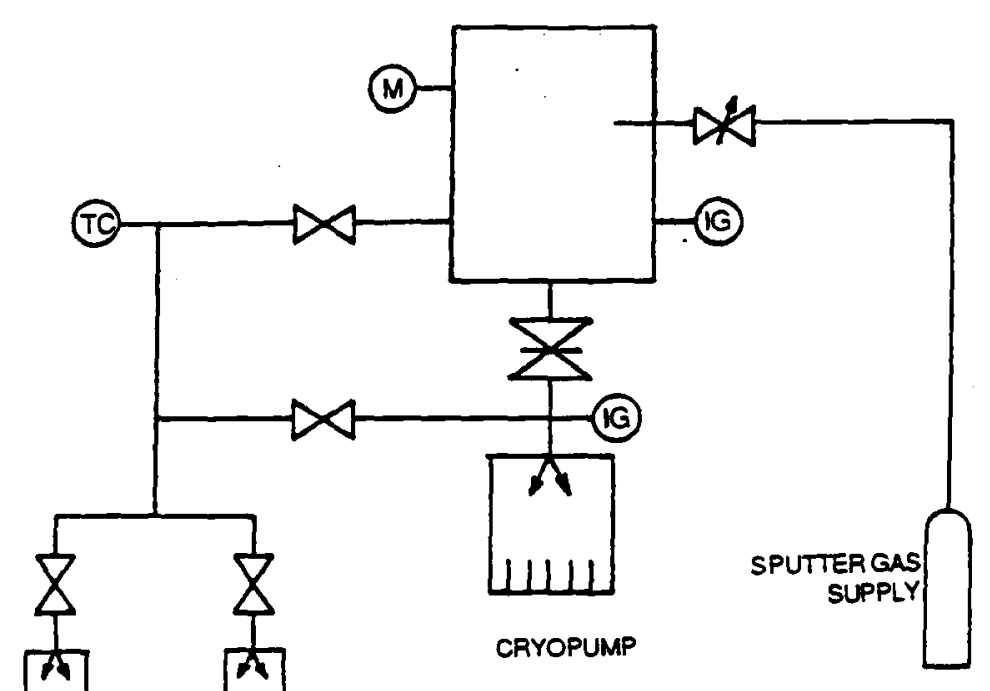

LIOUID NTROGEN SORPTION PUMPS

Fig. 1 Schematic diagram of the beryllium coating system.

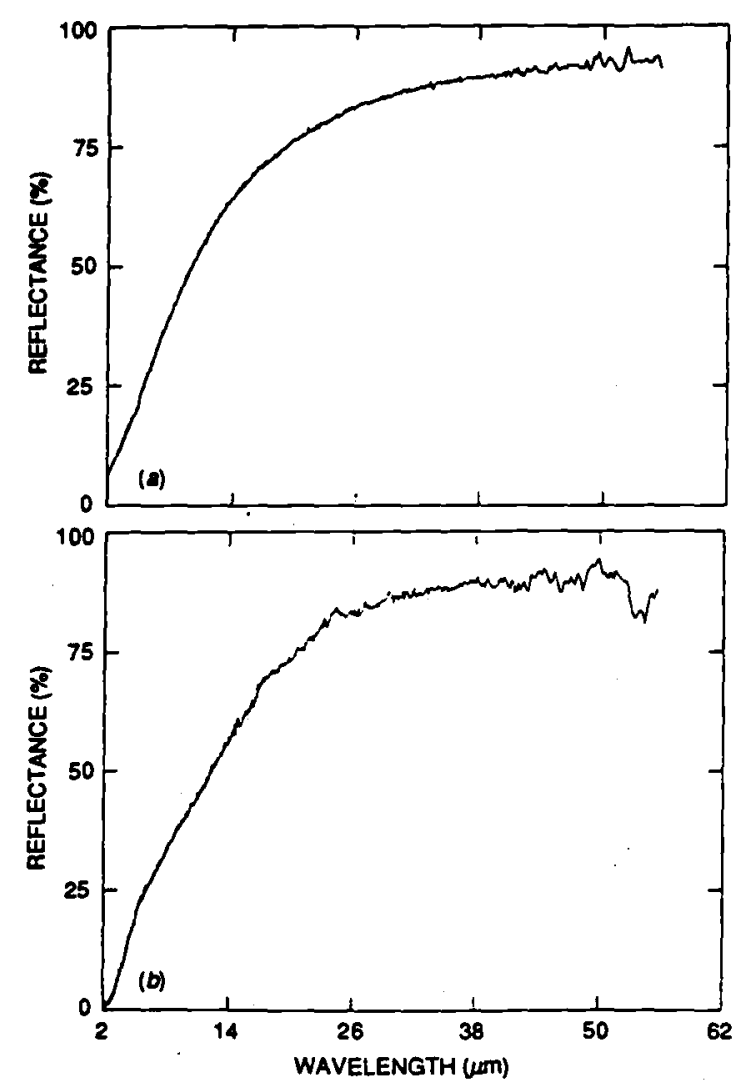

Fig. 2 Reflectance as a function of wavelength from $2 \mu \mathrm{m}$ to $50 \mu \mathrm{m}$ for etched beryllium from run 1 :

a) sample 2-C, $5 \mu \mathrm{m}$ thick and unetched;

b) sample 1-B2, $1 \mu \mathrm{m}$ thick with $60 \mathrm{~s}$ etch.
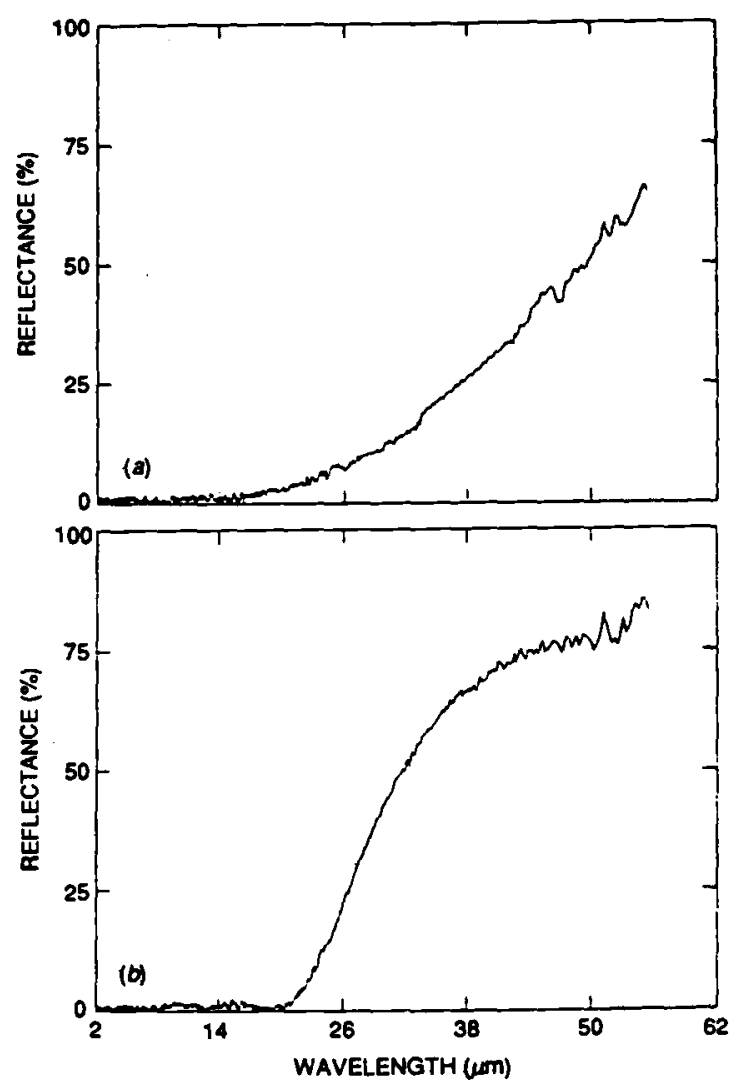

Fig. 3 Reflectance as a function of wavelength from $2 \mu \mathrm{m}$ to $50 \mu \mathrm{m}$ for etched beryllium from runs 2 and 3:

a) sample 2-B2, 5 um thick with 90 s etch;

b) sample 3-A1, $25 \mu \mathrm{m}$ thick with a $180 \mathrm{~s}$ etch. 


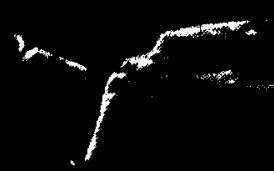

a) $1 \div$ 8000

527 1 (1)

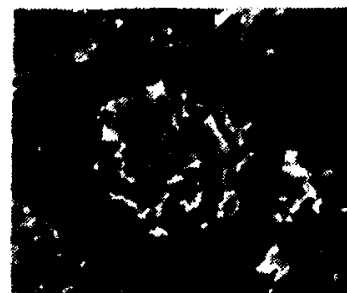

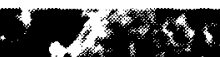

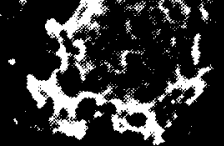
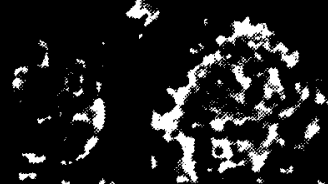

$\therefore$

F

$\lim _{1 \rightarrow \infty}+\infty$

c) 10 y $+3$

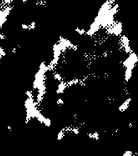

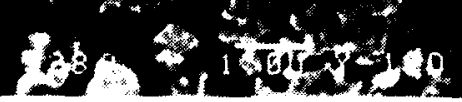

d) $15^{*}$

i

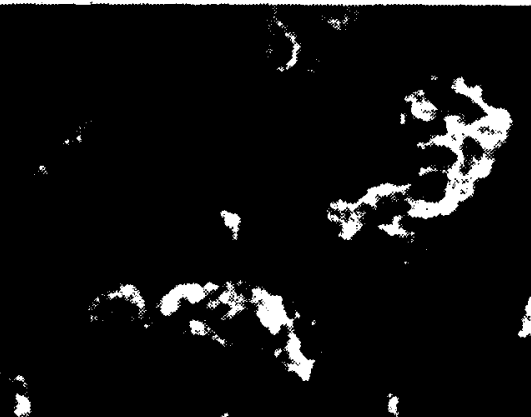

4
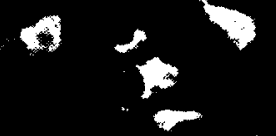

Fig. 7 Scanning electron micrograph of beryllium coating samples from run 3 which were etched for different times: a) 3-C, no etch; b) 3-B2, $30 \mathrm{~s}$ etch; c) 3-B1, $65 \mathrm{~s}$ etch; d) 3-A1, 180 s etch.
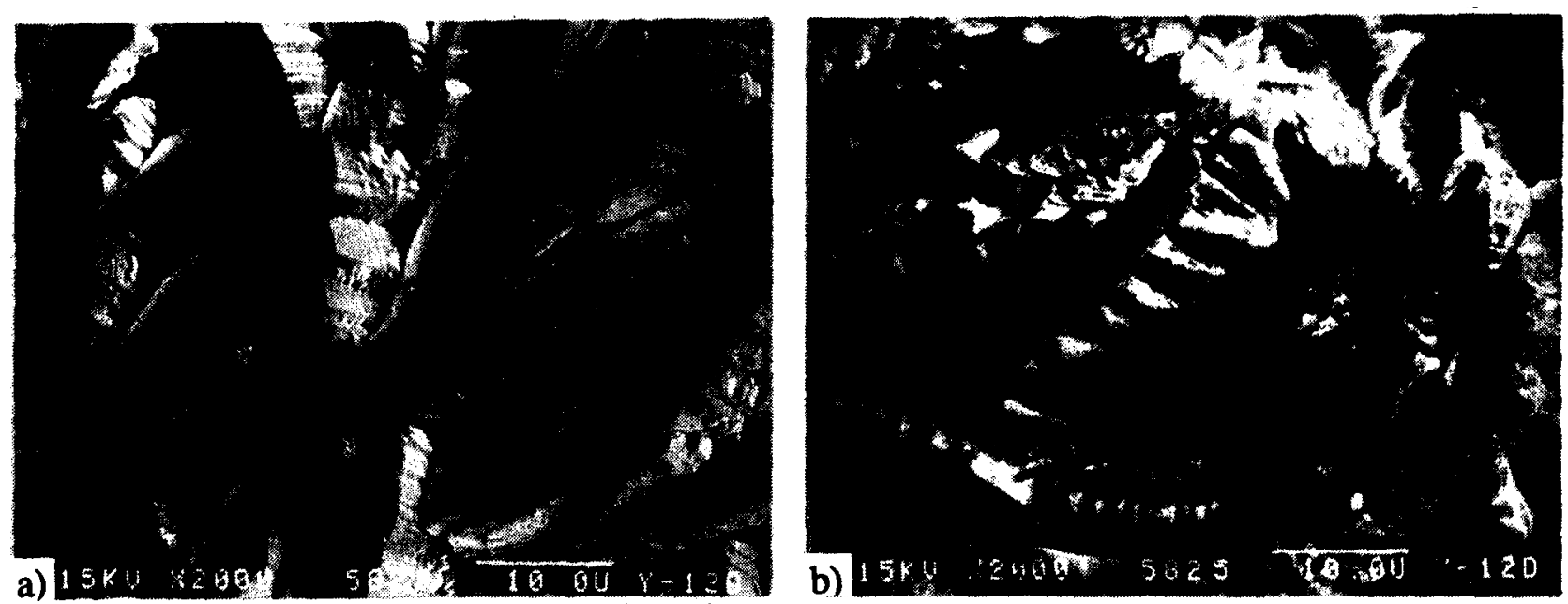

Fig. 8 Scanning electron micrograph of thick $(350 \mu \mathrm{m})$ beryllium coatings a) unetched sample $B Q-6$ and b) etched for $180 \mathrm{~s}$, sample BQ-4. 